Social Capital and Politeness Strategies

in Fostering Ethnic Relations in

Malaysia and Philippines

Maya Khemlani David

Francisco Perlas Dumanig 


\section{Social Capital and}

\section{Politeness Strategies in}

Fostering Ethnic Relations

\section{in Malaysia and Philippines}

Prof. M. Khemlani David

Professor, Faculty of Languages \& Linguistics,

University of Malaya, Malaysia

\section{Dr. F. Perlas Dumanig}

Sr. Lecturer, Faculty of Languages \& Linguistics,

University of Malaya, Malaysia 


\section{Social Capital and Politeness Strategies in Fostering Ethnic Relations in Malaysia and Philippines}

\section{Introduction}

Social capital helps in developing relationships among people in a community or from one community to the other. The concept of social capital focuses on social relationships or individual relationship which is an important tool in building a united and progressive society. Bourdieu (1997: 503) says that social capital centers on social relationships. More specifically, Putman (1993:167) explains that 'social capital' focuses on other qualities such as trust, norms, and networks. These qualities enhance the efficiency of a society by facilitating coordinated action. Putman (1993) posits that social capital can help a society in achieving goals and pursuing shared objectives. Social capital is essential for facilitating peaceful and effective relationships among people in a modern and progressive society.

Anything that facilitates individual or collective action generated by networks of relationships, reciprocity, trust, and social norms results in social capital (Coleman, 1988). Consequently, social capital can help in developing relationships of people through socialization and shared knowledge.

It goes without saying that in a multi-ethnic and multilingual society, social capital is necessary to help foster unity and harmony among various ethnic groups. However, such socialization and sharing of knowledge can be obstructed in multi-ethnic societies by social barriers in the form of negative preconceptions towards other ethnic groups. Stereotyping is the result of distancing due to prejudice, which is usually the result of ignorance of the values and culture of other groups.

\section{Malaysia}

In the case of Malaysia, it has been observed that polarization among Malaysian youth is common today as compared to previous generations. Research shows that in many public and private colleges and universities in Malaysia the majority of students group themselves according to their ethnicity (Chan, 2004; Fatimah, 1984).

Polarization is now evident among the ethnic groups in Malaysia and the concern at this phenomenon is often reflected in the speeches of government officials. For example, the Malaysian Deputy Finance Minister Datuk Ahmad Husni Mohamad Hanadzlah recently 
said that it was unfortunate that each race always stayed with their own. The preference of being with their own ethnic group is also the motivation behind Senator Datuk Zaid Ibrahim's decision to set up a foundation which will be activity-driven to give youths of different races the experience of being with each other so that they understand each other better.

The statements made by government officials emphasize the need to understand and foster better relationships between members of different ethnic groups in the country. It is trite knowledge that ignorance of others is often the basis for prejudice while understanding often results in trust and friendship. Moreover, understanding comes with knowledge of others and it through socializing that experience and knowledge of the other is obtained. When polarization is high, socialization with others is low. Limited socialization is a product of fear of the unknown and reactions based on negative stereotyping resulting in distrust and misunderstanding. If this phenomenon exists there is the absence of social capital.

The media also reinforces the stereotypes by reporting only the negative attributes of other groups. There is a constant emphasis on the failures and not the successes of societal achievement. Newspapers constantly lament the absence of national unity without pointing out areas where there is successful integration. Politicians and others often blame vernacular schools for this lack of unity without prescribing politically acceptable measures to improve the situation.. Some say that such lack of unity is due to the existence of ethnic based political parties as such parties often pursue the objectives of members of their group without regard for the interests of other ethnic groups. Sometimes in the reporting of news on crime there is a subtext or suggestion that certain categories of crime are committed by a certain race (Ponmalar, David \& Ramayan, 2009). It is possible that some or all of these factors contribute to racial polarization.

However, it might sometimes be more useful to try and promote the development of social capital by emphasizing the strong values and innate goodwill which is present in all communities instead of harping on the causes of racial polarisation. The fact of the matter is that Malaysians interact with each other all the time and in divergent settings especially in the public domain and the effectiveness of such interactions do often promote goodwill and understanding. Conscious awareness and sensitive communication strategies would facilitate such interaction. For a start it is important for Malaysians of all ethnicities to focus on similarities and common concerns as opposed to differences. Malaysia has been independent for half a century and it is important for Malaysians to take stock and assume responsibility for ensuring that goodwill prevails across ethnic groups. Making people realize that there is much that is common between people of all ethnicities will help to foster better relationships between people from the various ethnic groups. People have common aspirations, common concerns and common values. Most people in the world respect honesty and courage. All cultures have legends of heroism, where someone gives up his wealth or risks his life for the sake of truth. Similarly, 
independence is highly valued. It cannot be denied that although values vary from one society to the other there is broad commonality of values across different cultures and communities.

The three major ethnic groups in Malaysia, that is the Malays, Chinese, and Indians, have many commonly shared values. The previous Prime Minister Abdullah Badawi has often said that it is important for Malaysians to focus on the points that unite them rather than the points that divide them. These points that unite Malaysians include good behavior, good speech mannerisms, and the upholding of one's culture and traditions. Members of the three ethnic groups work hard to transmit these values from generation to generation. In fact, most elders, particularly grandparents who place much importance on these values, make it their responsibility to transmit these values to their grandchildren.

Family plays an important role in passing on the values from generation to generation because it is a key institution for the vertical transmission of instrumental values (Barth, 1969). Family is a integral unit of a society which shapes the values of children and the latter will eventually share the values which they learn from home with their friends Sharing common values and experiencing the fact that all Malaysians, irrespective of race and creed, are alike in so many fundamental ways, fosters unity. The sharing by individuals of these common values serve as their social capital, and can help them to develop better relationships with each other. Malaysians of all ethnicities must realize that such common values should adhere across racial and religious boundaries. In other words a young Chinese boy must be taught to respect an old Indian woman and to learn that honesty and courtesy are not just owed to members of one's own race or tribe. Where values are prescribed as being required only in transactions involving members of one's own race only, deep emotional and psychological schisms develop in individuals which could have long term implications. There are examples in history in which whites were taught that people of colour were lesser beings, for instance in South Africa under the apartheid system and in Nazi Germany where Jews were looked down as inferior people who deserved to be exterminated.

\section{The Philippines}

The Philippines is a multilingual and multicultural country consisting of 170 languages (Dumanig, 2007) and has a population of 88.57 million (National Statistics, 2008). People in the Philippines speak different languages and dialects however Filipino, the Philippine national language, is widely spoken. Apart from Filipino, English is also used as an official language which serves other functions specifically in government and education. Most Filipinos can speak English because it is used as the medium of instruction in the kindergarten, elementary, high school and college. 
Ethnic groups in the Philippines are not polarized. Although there are some cultural, linguistic and religious differences such differences do not cause polarization. Filipinos are generally regionalistic and yet nationalistic people. They have strong loyalty to their regions and this includes cultural and linguistic loyalty and also to their country in general and label themselves as Filipino regardless of their ethnic membership.

However, there are some parts in Southern Philippines particularly in Mindanao, where problems in ethnic relations exist. This is due to religious differences.. Most Muslims have strong affinity to their ethnic groups and religion. They are a minority and feel that they are neglected by the government.

This paper would like to examine how social capital helps in fostering unity among the three ethnic groups in Malaysia and the Philippines. More specifically, the use of politeness strategy to interact with people from various races such the use of address forms, respect for the elderly and non-verbal language.

\section{Politeness: Common value}

One common value across ethnic groups is the norm of politeness. Politeness would be associated with good behavior. Malaysians whether they are Malay, Chinese, or Indian often use common politeness strategies to facilitate discourse. Politeness is described by Mills (2003) as an expression of the speakers' intention to mitigate face threats carried by certain face threatening acts toward another. This means that politeness consists of efforts to save face for oneself or for another or as we say in Malay, 'menjaga air muka.' Face refers to the respect that an individual has for himself or herself, and it is important to maintain that "self-esteem" in public or in private situations.

Everyone has both a negative and positive face (Brown \& Levinson, 1987). Positive face is the positive self-image or personality that a speaker wants others to appreciate and approve. The negative face is the need to be unimpeded by others; usually, one tries to avoid embarrassing the other person, or making them feel uncomfortable. Face Threatening Acts (FTAs) are acts that infringe on the hearers' need to maintain his/her self esteem.

The concept of politeness strategies is categorized into four main types: bald on record, negative politeness, positive politeness and off-record or indirect strategy (Brown and Levinson, 1987). 


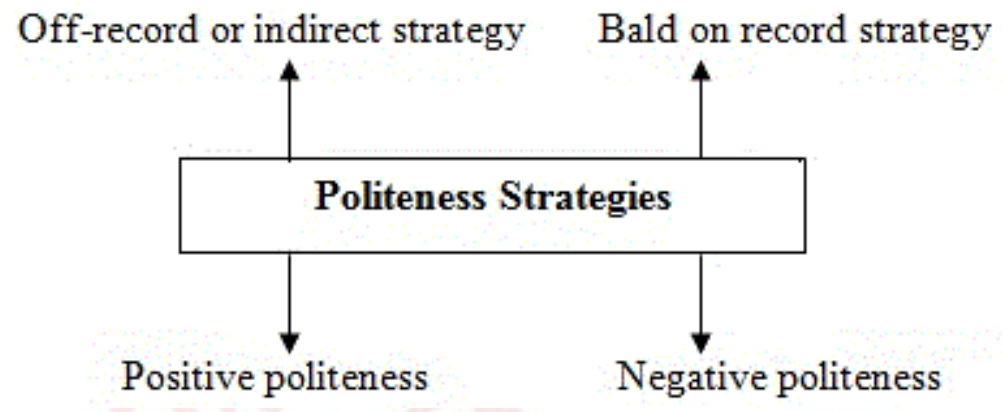

Positive politeness strategy occurs when the speaker attempts to minimize the threat to the interlocutor's or hearer's face. The reason for minimizing the threat is to establish a more cooperative and collaborative interaction between and among speakers. Moreover, proving a less face-threatening act will result in solidarity among the speakers. Positive politeness is made because of the speaker's intention to avoid conflict in an interaction. This happens when speakers hedge for instance instead of saying "no" they save the listener's face by saying "maybe" or "perhaps" in a situation where the intention is to say 'no'.

Off-record or indirect strategy occurs when a speaker impliedly states his or her intention or makes an indirect statement in order to prevent himself or herself from the potential of being imposing. For instance, if a speaker says "the radio seems to be loud", the speaker is subtly telling the other speaker that the radio is too loud and it would be better if the volume is reduced. However, the speaker tries to minimize the possible potential to impose something on to others. By using an indirect request he or she saves the face of the interlocutor.

In contrast, bald on record strategy is used when the speaker does not make any attempt to minimize the threat to the hearer's face. The message can be more direct and offensive to people who do not know the speaker well because direct imposition is used. One instance of using this strategy is by saying "Don't talk when your mouth is full." This may sound offensive if it is told to people who do not know the speaker well. However, it is not offensive when spoken by a mother to her child.

\section{Methodology}

This paper uses real time interactions among the Malays, Chinese and Indians in Malaysia and the ethnic groups in the Philippines. The analysis was focused on linguistic and non-linguistic features in interaction. The paper specifically analyzes the politeness strategies used in addressing people, expressing gratitude and using non-verbal language which serve as the common ground among people from different races. 


\section{Findings}

\section{Address forms}

Politeness strategies may appear in various forms and one of the common strategies to show politeness is revealed through the use of address forms. There is commonality among races and cultures as far as the use of address terms are concerned. Normally, people who are older than the speaker, high status individuals, older members of the family are addressed using appropriate terms of address because it is a sign of respect and politeness to people who are older and of higher social status. From this concept it can be said that politeness - specifically the use of appropriate address forms can be considered universal.

In the case of Malaysians, there are certain common grounds among the various ethnic groups which can be traced through the use of appropriate terms of address to show respect to interlocutors. Address terms like "Abang", "Cik", "Puan", and "Adik" are used to address different interlocutors as forms of respect. Commonly used address terms like "uncle and aunty" or "pak cik" and "mak cik", "ayak" (uncle), "apai"(grandfather) to refer to people older than the speaker are also used by many young Malaysians irrespective of their ethnicity (see Examples 1-3). In Sarawak, once a couple has a child, they will be addressed as "so and so's father or mother", e.g. "Bapak Miki, Emak Miki." Punjabis use the address marker "ji" to indicate respect to an older interlocutor. "Thamby" is used to refer to a younger Indian boy while "Ayah" is used to address an older Indian man.

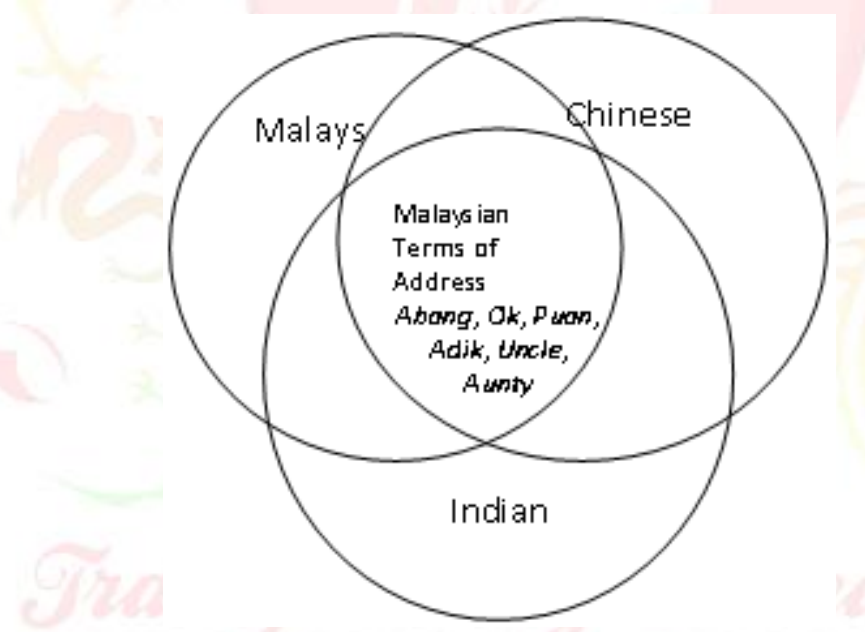

Integration of Terms of Address in three Ethnic Groups 
In the Philippines the use of "sir"(male), "kuya" (elder brother), "maam"(female), "ate" (elder sister), "tito" (uncle), "tita" (auntie), "lolo" (grandfather) and "lola" (grandmother) are commonly used as address forms in the Tagalog region. These terms of address are used when showing respect particularly when a speaker is younger, and of low status. "Sir" and "kuya" are used when addressing a male interlocutor older than the speaker. However, if the interlocutor is of higher status, he will be addressed as "sir". The address form "kuya" is also used to address an elder brother within the family. The use of "maam" and "ate" has similar function with "sir" and "kuya". The only difference is that "maam" and "ate" are used to address women. "Tito", "tita", "lolo" and "lola" are used when addressing older interlocutors.

Example 1: A Malay (A) talking to another Malay (B)

A: Encik Johan

B: Hi, what do you think of my presentation, what did you remember?

A: I remember club pintu.

Example 2: A Chinese (A) talking to a Malay (B)

A: Mak cik ini berapa? (Aunty how much is this?)

B: Empat ringgit lah. (Four ringgit)

Example 3: An Indian (A) talking to a Chinese (B)

A: Uncle, how much going to Midvalley?

B: Ten rinngit.

Example 4: A Filipino (A) talking to another Filipino Chinese (B)

A. Kuya, pwede po bang magtanong? (Brother, can I ask a question?)

B. Ano yun? (What is that?)

Example 5: An interaction of two Filipino interlocutors in a workplace.

A. Good morning maam, bago yata ang damit natin ngayon. (.....it seems you have a new dress today)

B. Hindi, luma na to. (no, this is old)

Example 6: An interaction at home of a younger and older Filipino.

A. Uncle saan ang punta nyo ngayon? (Uncle where are you going today?)

B. Punta ako ng MOA. (I'm going to MOA) 
Honorifics are also used to indicate politeness (see Examples 4 and 5). When the honorific forms used are appropriate according to socially expected norms, they reflect appropriateness of context, and can best be understood as linguistic politeness rituals. A substantial amount of politeness is performed by people acting in accordance with socially expected norms. One of the overlying strategies of positive politeness is to establish common ground, and it is in that connection that the use of such linguistic rituals as honorifics works as politeness (Ide, 1992).

Example 7: Malaysia

Perak police chief Datuk Zulkefli Abdullah said police had taken statements from them. (The Sun, May 27, 2009, p. 5, Police arrest 19 over planned hunger strike)

Example 8: Philippines

Maj. Harold Cabunoc, spokesman of the Army's 9th Infantry Division, said military trucks started evacuating the residents living at the foot of the volcano soon after they received a report of the explosion.

(The Philippine Star, February 19, 2011. Bulusan eruption prompts evacuation of 2,000 people.

http://www.philstar.com/Article.aspx?articleId=659581\&publicationSubCategoryId=200)

The use of address terms is perceived to be polite across many ethnic groups in the country. When a speaker does not use any terms of address particularly in dealing with adults or people of higher rank or social status, this is perceived to be impolite. It is a good sign that people from different ethnic groups in the country put the same premium on using appropriate address markers as politeness strategies. The use of terms of address as politeness strategy serves as social capital among Malaysians.

Due to language differences, people in the Philippines use different address forms. Using the correct and appropriate terms of address is deemed to be polite. For instance "Attorney" (Atty.) is used when addressing a lawyer, "Engineer" (Engr.) when addressing a licensed engineer.

In Sarawak honorifics are used when addressing the chief minister as Pehin Seri as he is the only one in the State with such a title. Other honorifics used in Sarawak are "Datuk Patinggi" and "Datuk Amar." In Sabah honorifics include "Datuk Panglima", "Datuk Paduka" and "Wali Kota." 
Example 9: A Malay lecturer (A) talks to her Dean (B), a Chinese.

A: Prof. Lee will the meeting start at 2:30 pm on Wednesday?

B: Yeah, that will be from 2:30 to 5:30.

Example 10: An interaction between a Filipino lawyer and a Filipino client. A. Atty. Perez, I will give you the details of the case next week.

B. Sure. Thank you.

\section{Respect for the elderly}

An aspect of politeness common to all ethnic groups is respect for the elderly. Respect can be shown linguistically by using some address terms like "Abang, Puan, Uncle, Aunty, Apai, Indai (Iban), Inak (grandma - Kadazan)" or some polite words such as please, kindly, saying thank you after a favor is given, and using hedges to appear indirect when making requests Sarawak Malays use terms such as 'kitak' (you) and 'kamek' (I) to show respect to the elderly rather than 'kau' (you) and 'aku' (I). Peninsular Malaysians after being in Sarawak for a short period are able to accommodate and use these terms when addressing Sarawakians.

It is also common among Malaysians irrespective of ethnicity to accommodate to certain discourse norms when talking with the elders. Talking to the elders is guided with discourse practices like allowing the elders to initiate and control the discussion. When a young speaker initiates and controls the talk it is normally frowned on by the elders and is perceived as disrespectful behavior. Interrupting an older person whilst he is in the midst of an utterance is also universally deemed impolite across many ethnic groups in the country. The younger person uses body signals and eye contact rather than verbal interruption.

In the Philippines, Tagalog speakers show their respect to elders linguistically by using "po" or "ho." Failure to use either of the two lexical items will be considered impolite.

\section{Expressing gratitude}

It is also expected that after receiving any favor, every individual must show his or her gratitude to the giver by saying "thank you", "terima kasih" or " xiexie" (see Example 6). In the Bidayuh community where there is no direct equivalent term for 'thank you' a person often reciprocates by giving something in return. This form of exchange is also common among Sarawak Malays during Ramadan and is called 'balas' Thus politeness is not limited to the use of words but also includes the use of appropriate non-verbal signs. 
Similarly, in the Philippine context, saying "thank you" or "salamat" is obligatory when a favor or appreciation is made. Without expressing a gratitude is considered to be impolite and disrespectful to the person who gave the favor.

Example 11: A young Chinese customer (A) talks to a Malay vendor (B)

A: Ma cik, ada baru? (Aunty, do you have something new?)

B: Yah, ada. (Yes, there is)

A: Terima kasih. (Thank you)

Example 12: A Filipino who gives his friend a book

A: Bumili ako ng dalawang libro kahapon. (I bought two books yesterday.) B: Anong book? (What book?)

A: Ito, ibigay ko na to sayo. (Here it is. I'll give it to you)

B: Naku, maraming salamat (Oh, thank you very much)

\section{Non-verbal language}

One common non-verbal sign indicating politeness is using the thumb when pointing to things or people. If someone points to something particularly when talking to the elders, it is expected that the thumb will be used in pointing. When a finger is used, it can be interpreted as rude and impolite. This verbal sign is no longer limited to the Malay community. In fact, other minority communities in the country have accommodated and begun to use their thumbs when they point to something. Accommodation and adaptation to such non-verbal norms in relation to politeness and respect is the essence in forming social capital. When passing in front of a group of elders who are talking, a younger member will automatically bend his/her body and lower his/her hand as though to touch the ground. When an elder Bidayuh joins a conversation, out of politeness the younger Bidayuhs will switch to the Bidayuh dialect which is comfortable to the elders. When people visit the home of Bidayuhs they greet their guests by saying "Please make yourself at home." This is comparable to the traditional Sindhi greeting which is "My home is your home."

Malays kiss the hands of the elders to indicate respect, while Indians touch their elders' feet to indicate respect. Chinese put their hands together and bow. Similarly, in the Philippines kissing the hands of the elders is one way of showing respect. Despite the different ways of doing things, the common ground is to show respect to the elderly which is also manifested through the use of appropriate terms of address and non-verbal signs. Furthermore, in giving and receiving something from the elders, the use of the right hand is preferred. Using the left hand is regarded as rude by Malaysians. 


\section{Conclusion}

In addition to politeness there are other values common to all races and cultures that constitute social capital. Emphasis on these similarities would help to build social capital which in turn would help to foster national unity. In addition people will understand better the cultural values and norms of other ethnic groups. The realization that there are so many similarities in diverse cultures will grow. Focusing on similarities of the cultural and social values particularly in showing politeness can help promote better understanding among ethnic groups. When people understand each other and become aware of each other's norms and practices, unity would be advanced.

It is difficult or impossible to distinguish social capital from values. It has been mentioned that people learn to come together with others who possess similar values. Thus, people sharing similar values may have greater possibilities of dealing with each other harmoniously. Malaysia and the Philippines with such a diverse population are well placed to show the world that social capital can lead to better relationships between people of different races and ethnic groups. Ethnic boundaries need not be insurmountable barriers, as people with shared or common values can come together and co-exist harmoniously to pursue shared objectives bonded together by shared experiences.

It is evident that politeness as a discourse strategy is highly valued among Malaysian ethnic groups whether Malays, Chinese or Indians. The similarities of the cultural and social values among the Malays, Chinese and Indians for instance, the use of address terms, non-verbal signs and discourse norms in interaction as politeness strategies within their ethnic groups or across the major ethnic groups foster better and harmonious relationships. Similarly, in the Philippines different ethnic groups from the various regions of the country are able to share the same culture and values when interacting with one another. Learning different terms of address, non-verbal features in communication and discourse styles from other ethnic groups helps in fostering better relationship.

As a cautionary note, we repeat the point that it is not enough that values of a community are only observed within and by that community. It is essential that they are observed across all communities. Respect is owed by all to all and that constitutes social capital which will help promote understanding and unity. Politeness aside there are other cultural values and practices common to all cultures like honesty, courage, trust, truthfulness that would foster unity and nation building. However, shared values alone may not be sufficient in Malaysia and the Philippines given their peculiar complexities unless they transcend the social plane. There must also be measures in place to make sure that all races and ethnic groups benefit equitably from Government programmes for the education, health and welfare. Shared values will then have a meaningful context. The need to ensure the equitable distribution of wealth and opportunities across racial or 
ethnic and class divides is vital. In other words it is not only politeness and communication norms that are essential. Underpinning societies must be shared values which promote justice and fairness for all. There must be the rejection of ideologies or social or political constructs that place one group as being superior or better than another.

\section{References}

1. Barth, F. (1969) Ethnic groups and boundaries. Long Grove, Ill: Waveland Press, Inc.

2. Bourdieu, P. (1977). "Cultural Reproduction and social reproduction," in Power and Ideology in Education, eds. Jerome Karabel and A. H. Halsey. New York: Oxford University Press.

3. Brown, P. \& Levinson, S. (1987). Politeness: Some universals in language usage. Cambridge, England: Cambridge University Press.

4. Chan, H. C. (2004). Racial polarisation and room-mate choices among university students. In Cheah Boon Kheng. The challenge of ethnicity: Building a nation in Malaysia (pp. 9-39). Singapore: Marshall Cavendish International.

5. Coleman, J. C. (1988). 'Social capital in the creation of human capital' American Journal of Sociology 94: S95-S120.

6. Dumanig, Francisco. (2007, July). Analysis on the language choice and marital typology of South-East Asian couples. Paper presented at the 2nd Singapore Graduate Forum on Southeast Asian Studies. Singapore.

7. Fatimah Daud. (1984). Some patterns of ethnic relations in Malaysia. Asian Profile, 13(2): 117-28.

8. Ide, S. (1992). On the Notion of wakimae: Toward an integrated framework of linguistic politeness. In Kotoba no mozaiku. Okuda Natsuko Meiyo Kyōju Koki Kinen Ronbunshū (pp. 298-305). Tokyo: Mejiro Linguistic Society,.

9. Mills, S. (2003). Gender and politeness. Cambridge, England: Cambridge University Press.

10. National Statistics (2008) Philippine Population. Retrieved June 7, 2008 from http://www.census.gov.ph/data/pressrelease/2008/pr0830tx.html

11. Ponmalar N. A., M.K. David \& Sri Kumar Ramayan. (2009). Representation of a minority Community in a Malaysian Tamil daily. Language in India. 9:3. http://www.languageinindia.com/jan2009/mayanotionalismalaysia.html

12. Putnam, R. D. (1993). Making democracy work. Civic traditions in modern Italy, Princeton, NJ: Princeton University Press. 


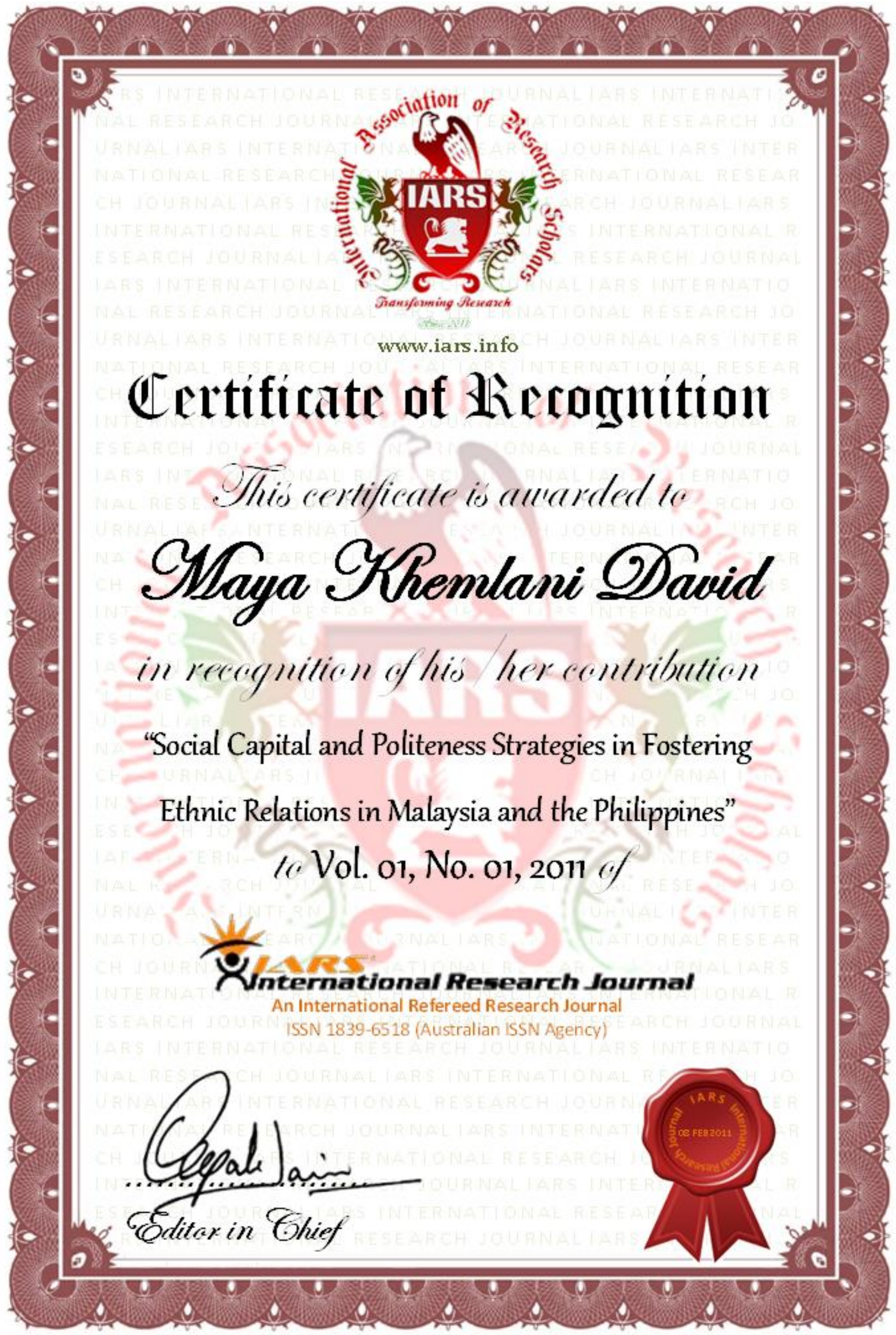

